\title{
Journal of Electron Spectroscopy and
} Related Phenomena

\section{Foreword}

Almost everyone dealing with surface analysis of insulating materials has encountered blurring/shifts of the images and/or the peaks due to sample charging, and has also learned how to cope with this "nuisance", thanks to excellent technical developments all along. Only very few researchers have thought of benefiting from this shortcoming and turned it into "a blessing", like most of the authors in this issue. Therefore, the present special issue has been put together to review and highlight the recent work of some prominent scientists around the world dealing with the "charging". We hope that this issue will add to a better understanding at the molecular level, of this very fundamental phenomenon, which is well known to humankind for more than 25 centuries.

I am grateful to Jean-Jacques Pireaux for suggesting the idea, to Michael Kelly for writing the "Historical Perspective", to Peter
Sherwood for preparing the "Preface", and to all the authors who have put together the following excellent manuscripts. Last but not the least, I thank all the reviewers for their time and effort.

Guest Editor Sefik Suzer* Bilkent University, Department of Chemistry, 06800 Ankara, Turkey

*Tel.: +90 312290 1476; fax: +90 3122664068 . E-mail address: suzer@fen.bilkent.edu.tr Available online 21 October 2009 